\title{
COORDINATION SYSTEM FOR INDONESIAN DISASTER RELIEF DISTRIBUTION OPERATIONS THROUGH INFORMATION SYSTEM
}

\author{
Irma Dwiputranti ${ }^{1}$, Adriyani Oktora ${ }^{2}$, Liane Okdinawati ${ }^{3}$ \\ 1. Polytechnic Pos Indonesia, 2. Polytechnic Pos Indonesia, 3. School of Business and \\ Management, Bandung Institute of Technology \\ Corresponding author: aneu.okdinawati@gmail.com
}

\begin{abstract}
A disaster is an event caused by several factors such as natural and/or nonnatural factors and human factors. Disaster not only threatens and disrupts people's lives but also will cause human casualties, environmental damage, property loss, and psychological impact. One of the challenges in disaster management is how disaster management conducted that include distribution of disaster relief can be done quickly, effectively and efficiently and also channeled to disaster victims. Moreover, when conducting disaster management, the authority often faced several problems such as the process of distributing disaster relief often encountered barriers; disaster victims received late disaster assistance or even cannot receive disaster assistance in accordance with their needs. Therefore, information system application is needed to assist in the process of distribution, coordination, management, and monitoring of disaster relief. The information system is designed to improve the performance of disaster relief operations that can be used by all parties including Government, NGO, and private parties, even the public. The information system is expected to be used as a coordination tool and medium that can integrate all parties involved in order to improve the disaster relief distribution operations effectively, efficiently, and transparently.
\end{abstract}

Keywords: disaster management, disaster relief operation, information system, coordination, distribution, monitoring.

\section{Introduction}

Disaster is an event caused by several factors such as natural and/or non-natural factors and human factors. Disaster not only threatens and disrupts people's lives but also will cause human casualties, environmental damage, property loss, and disaster victims affected psychologically. The impacts of a disaster are not just the onset of many casualties, but property losses, infrastructure damage, and psychological impact are inevitable. Indonesia has geographical, geological, hydrological, and demographic conditions that make Indonesia one of the most vulnerable countries associated with natural disasters. 
This disaster management is needed in the event of a disaster. Disaster management includes the process of distributing logistic assistance for disaster victims, where in the implementation of this distribution must be at the right time, appropriate location, on target and in accordance with the needs of disaster victims. In conducting disaster management, various actors are involved not only limited to government engagement but also NGOs, community, and private parties. All parties involved should conduct this disaster management in an integrated manner. Other parties such as public can participate as donors or volunteers, private companies also can involve as collectors or providers depend on their expertise and interest. One of the challenges in disaster management is how disaster management that include disaster relief distribution can be done quickly, effectively and efficiently and also channeled to disaster victims. When conducting disaster management, the authority often faced several problems such as the process of distributing disaster relief often encountered barriers; disaster victims received late disaster assistance or even cannot receive disaster assistance in accordance with their needs. Therefore, in order to assure disaster victims receive disaster assistance in accordance with their needs, coordination among all parties is necessary to be implemented. Moreover, accurate and effective information is an important aspect for early warning and monitoring (before disasters) and during and after disasters. In order to manage the information, it is necessary to involve and coordinate all parties in delivery of relief assistance, monitoring, and evaluation relief operations. Information system can be used to manage the information by developing tracing and monitoring system to provide concise information on disaster assistance, and clearly indicate the distribution process and disaster relief needed by the victims.

Indonesia has several information systems as early warning system to help disaster management run smoothly in preparation stage of disaster management. However, Indonesia government has not used information system in response stage. Therefore, this paper aims to propose information system as coordination system for Indonesian disaster relief distribution 
operations to help the process of distribution, coordination, management, and monitoring of disaster relief. The coordination system through information system is expected to be used as a coordination medium that can integrate all parties involved in disaster relief distribution operations in order to improve effectively, efficiently, and transparently.

This paper is organized as follow; the related method to develop the information system is presented in Section 2, while the conceptual framework of information system is presented in Section 3. Next, the discussion explained in Section 4. Finally, the conclusions are given.

\section{Method}

Laudon, Laudon, \& Elragal (2012) stated that information system defines as interrelated technology (hardware, software, and data), people, and process. The information system is used by decision maker to support and control decision-making processes, coordination decision support system, and used as analysis tools by collecting, filtering, processing, creating, storing, and distributing the information (Laudon et al., 2012). Coordination system is developed in this paper to accommodate functional perspective and structural perspective of information system. Hirschheim, Klein, \& Lyytinen (1995) stated that information system fulfils functional function as an instrument to help decision-maker to record, store, and distribute the information. Moreover, Hirschheim et al. (1995) also stated that information system also fulfil structural perspective when the information system can be useful in accordance with the purpose of organization or its function.

\section{Technology}

The coordination system is developed for use in different type of hardware from computer, tablet, and smart phone. This type of hardware is chosen based on consideration that the information system is used by different parties i.e. government, NGOs, community, and private parties, and can be used everywhere and every time. Based on the hardware used for the coordination system, Microsoft Windows 7 is used as operational system 
on computer and Google Android is used as operation systems on the smart phone and tablet.

In information system, data is utilized into information in order to generate knowledge that can be used for decision-making (Hirschheim et al., 1995). MySQL is used in this coordination system database to organize collection and related information. For this coordination system, different type of data from different parties is collected. The information system also used to improve operational performance in distribution process as mention by Wullur \& Wardaya (2015).

2. People

In humanitarian relief-operation management involved different players that has different purposes, interests, and expertise (Balcik, Beamon, Krejci, Muramatsu, \& Ramirez, 2010). Different players can be classified into four main groups: government, providers, collectors, and donors. The government is the only player that has a role as activators of disaster relief operations, due to only the government has the authority to mobilize resources for disaster relief operations. In Indonesia, the government can be divided into central government, local government, and aid agencies that are managed by government known as Indonesian National Board for Disaster Management (BNPB). The government also has a key role to make protocols and take action for involvement of other countries and the international community.

Providers have a role to ensure the necessary material and resources available for operational needs and support (Blecken, 2010). Providers are required in making the distribution of disaster relief more efficient. The company as a provider can contribute by providing disaster relief goods, services, and their expertise as donation. Several companies that have a role as provider i.e. transportation companies as logistics companies give their delivery/pick up service and expertise; hospital can become providers by offering their health expertise or health goods; communication company offers their communication services to help coordination and monitoring run smoothly, and so forth . Military also appertain as provider 
by offering their expertise to help government in preparation and response stage.

Collectors are the company or Non-Governmental Organization (NGOs) to collect the fund aid or disaster relief. Collectors' role is needed in order to increase speed and efficiency of relief efforts as the partners of humanitarian organizations. The collectors also have a role as assistant to providers during the distribution process. Various companies belong to collectors groups i.e. banking companies to collect fund aid from donors. Warehouse companies as logistics companies to collect different type of disaster relief from donors. In this study the collectors and providers must be approved by the government or BNPB in order to maintain the transparence of information, ease coordination process, and simplify the process of disaster relief received for the victims.

Donors are individuals and/or communities that contribute in disaster relief. In general, donors can give two types of donation such as in-cash donations to support disaster relief operations financially or in-kind donations by donating goods and/or services. Van Wassenhove \& Martinez (2012) stated that many donors often donated unsolicited donations of old goods and perishables. This happens due to donors only donate what they want to donate not based on the disasters victims needs.

\section{Process}

A process model is used to describes business processes and the activities that people do and it is developed for the system and/or to be the system (Dennis, Wixom, \& Roth, 2012). Data flow diagram (DFD) also used as a technique that represents the connections of business processes and the data used in the business process (Dennis et al., 2012). The use case diagram was also used in this paper to illustrate how the business goes from all parties point of view that represented by stick figures.

Information system in this study was developed to help the distribution process of disaster relief to the victims. Moreover, the information system was developed to integrate and coordinated different players in humanitarian relief operations. The information system would be 
controlled and managed by BNPB. The information system was used as real time monitoring system by the central government as an information dashboard, eased government on making the report, and also used to alert about the real time condition of the victims needs. Each party involved had a different role and had different access whether to update the information or to see the information in BNPN Applications (Website or Android).

4. Results

A process model describes business processes and the activities that people do and it is developed for the system and/or to be the system (Dennis et al., 2012). There are several actors involved in the operation of BNPB information systems, which are as follows: (1) Government is the only player that has a role as activators to authorize disaster relief operations and mobilize resources to disaster area. Moreover, the government also has a fundamental role to make protocols and take action for involvement of other countries and the international community; (2) In Indonesia, government can be divided into central government, local government, and aid agencies that are managed by government known as Indonesian National Board for Disaster Management (BNPB). BNPB has a function as an institution to provide guidelines and direction on disaster management, provide inputs and suggestions for central governments, coordinate and command disaster management effectively and efficiently; (3) Providers are required in making the distribution of disaster relief more efficient. A company as a provider can contribute by providing disaster relief goods, services, and their expertise as donation. Several companies that has a role as provider i.e. transportation companies as logistics companies give their delivery/pick up service and expertise; hospital can become providers by offering their health expertise or health goods; communication companies offer their communication services to help coordination and monitoring run smoothly, and so forth. Military also appertain as provider by offering their expertise to help government in preparation and response stage; (4) Collectors are the company or NonGovernmental Organization (NGOs) to collect the fund aid or disaster 
relief. Collectors' role is needed in order to increase speed and efficiency of relief efforts as the partners of humanitarian organizations. The collectors also have a role as assistance to providers during distribution process. Various companies belong to group of collectors i.e. banking companies that collect fund aid from donors, or warehouse companies as logistics companies that collects different type of disaster relief from donors. In this research, the collectors and providers must be authorized by the government or BNPB in order to maintain the transparence of information, ease coordination process, and simplify the process of disaster relief done for the victims; (5) Donors are the ones who donate disaster relief. In general, donors can give two types of donation such as in-cash donations to support disaster relief operations financially or inkind donations by donating goods and/or services.

The outline of the information system for distribution disaster relief in this study can be in shown in Figure 1. In Figure 2, it can be seen the use case diagram for interaction among actors in BNPB information systems.

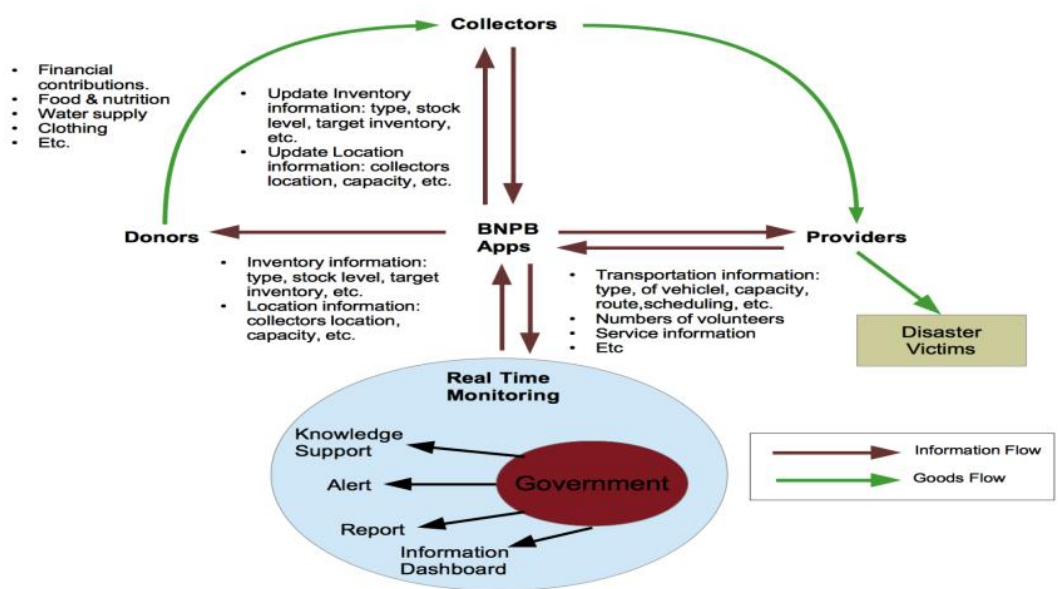

Figure 1. Design of Indonesian Disaster Relief Distribution Operation Information System 


\section{Discussion and Results}

Using BNPB Applications (Website or Android), donors can see the information related to what kind of disaster reliefs needed by the victims. The stock level, and target inventory needed. This information is needed in order to reduce donors donating unnecessary goods. Donors also can find where the authorized collectors location. This information will help donors decide to which collectors they will send the disaster relief. Based on that, donors only can see the information in BNPB Apps. Donors cannot change or add the information in BNPB Apps. Donors can choose what type of disaster relief they will give such as financial contributions, food or nutrition, water supply, clothing, etc. based on the information from BNPB Apps.

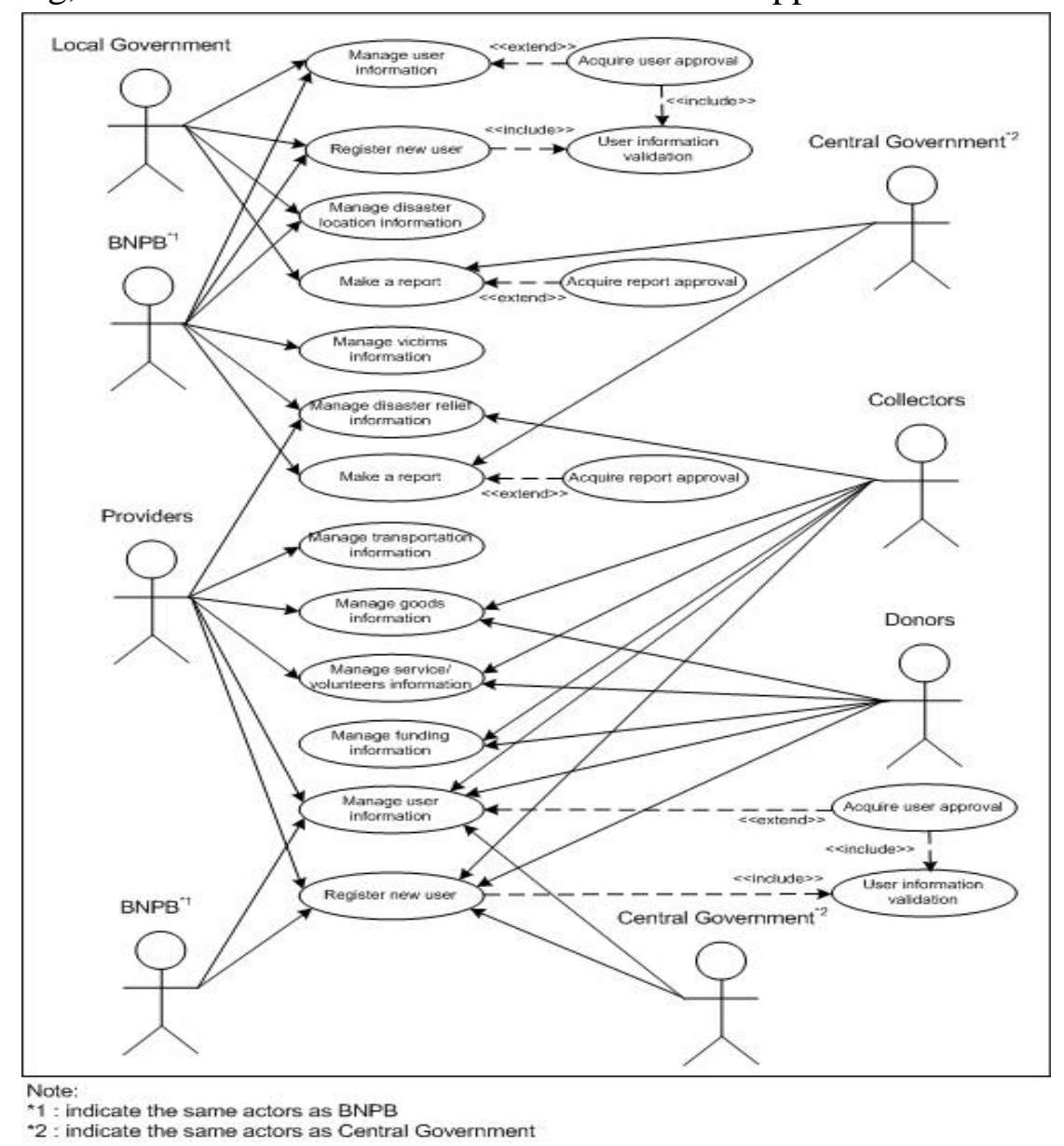

Figure 2. Use Case Diagram of Information System for Indonesian Disaster Relief Distribution Operation

As collectors, their responsibility is to collect all disaster relief from donors and update the information in BNPB Apps. The information is related 
to inventory information such as type of disaster relief needs, stock level, etc. Collectors' location is also updated if the location of collectors changes. Inventory information and location information are needed by providers to organize pick up process from collectors to the victims. Therefore, providers through BNPB Apps can access inventory information and collectors' location information. Providers can access BNPB Apps not only to get collectors information but also to update information related to pick up process such as transportation network and transportation information (type of transportation mode, delivery schedule, etc.). Other companies (ex. Hospitals) as providers can update the information related to their services such as numbers of volunteers or information related to drug/health aspects, and etc.

Collectors can give notification and alert to providers when the best time or possible time disaster relief can be taken by providers. Providers also can give notification and alert to collectors when to pick up disaster relief, what type of disaster relief to be picked up, and numbers of disaster relief to be picked up. BNPB can give notification and alert to collectors and providers through BNPB Apps concerning to the urgency of disaster relief needs by the victims. Providers also can give local government and BNPB notification as the authority in disaster location when to deliver disaster relief, what type of disaster relief to be delivered, and numbers of disaster relief to be delivered. The used of information system for providers is to help providers distributed disaster relief on time. This is inline with Firdaus \& Pertiwi (2016) research that mentions one of the causes of delivery errors is the misinformation received by the providers. Through BNPB Apps, government used all the information as information dashboard to organize and manage the situation more efficient and effective.

\section{Conclusion}

Accurate and effective information is crucial during disasters and helps coordination and monitoring process of distribution disaster relief run 
smoothly. Many parties are involved in humanitarian relief-operation such as government, donors, collectors, and providers. Each party has different roles, purposes, interests, and expertise. In this paper information system is utilized to manage the information, to help the process of distribution, coordination, management, and monitoring of disaster relief.

This paper provides insight development of conceptual framework of information system design as coordination system to help disaster relief operations done quickly, effectively and efficiently. All parties involved will use the information system as a coordination tool, where each party has different responsibilities and different access right depend on their role in humanitarian-relief operation. This information system is expected to reduce donors donate unsolicited donations, give real time information, facilitate the coordinate process, and can be used by all parties anywhere. If required, they should be used only for brief notes that do not fit conveniently into the text.

\section{References}

Balcik, B., Beamon, B. M., Krejci, C. C., Muramatsu, K. M., \& Ramirez, M. (2010). Coordination in humanitarian relief chains: Practices, challenges and opportunities. International Journal of Production Economics. https://doi.org/10.1016/j.ijpe.2009.09.008

Blecken, A. (2010). International Journal of Physical Distribution \& Logistics Management Supply chain process modelling for humanitarian organizations Supply chain process modelling for humanitarian organizations. International Journal of Physical Distribution \& Logistics Management International Journal of Physical Distribution \&amp Logistics Management Iss International Journal of Physical Distribution \&amp Logistics Management.

Dennis, A., Wixom, B. H., and Roth, R. M. (2012). System analysis and design. John Wiley \& Sons, Inc.

Firdaus, M. I., \& Pertiwi, S. (2016). Penyebab Terjadinya Pengiriman Barang Misroute. Jurnal Manajemen Bisnis Transportasi Dan Logistik, 2(3), 420-432.

Hirschheim, R., Klein, H. K., \& Lyytinen, K. (1995). Information Systems Development and Data Modeling: Conceptual and Philosophical Foundations. Information Society. https://doi.org/10.2307/40324236

Laudon, K. C., Laudon, J. P., \& Elragal, A. (n.d.). Management Information Systems MANAGING THE DIGITAL FIRM.

Van Wassenhove, L. N., \& Martinez, P. A. J. (2012). Using OR to adapt 
supply chain management best practices to humanitarian logistics. International Transactions in Operational Research. https://doi.org/10.1111/j.1475-3995.2011.00792.x

Wullur, M., \& Wardaya. (2015). Praktik Manajemen Rantai Pasok dan Teknologi Bisnis Berbasis Elektronik sebagai Pemoderasi Perusahaan Manufaktur. Jurnal Manajemen Transportasi \& Logistik, 2(2), 143-157. 